\title{
Low voltage CMOS power amplifier with integrated analog Pre-Distorter for BLE 4.0 application
}

\author{
Selvakumar Mariappan ${ }^{1}$, Jagadheswaran Rajendran², Norlaili Mohd Noh ${ }^{3}$, Harikrishnan Ramiah$^{4}$, \\ Asrulnizam Abd Manaf ${ }^{5}$, Shukri Korakkottil Kunhi Mohd ${ }^{6}$, Yusman Mohd. Yusof ${ }^{7}$ \\ ${ }^{1,2,5,6}$ Collaborative Microelectronic Design Excellence Centre (CEDEC), Universiti Sains Malaysia, Malaysia \\ ${ }^{3}$ School of Electrical \& Electronic Engineering, Universiti Sains Malaysia, Malaysia \\ ${ }^{4}$ Department of Electrical Engineering, Faculty of Engineering, Universiti Malaya, Malaysia \\ ${ }^{7}$ Silterra Malaysia Sdn. Bhd, Kulim Hi-Tech Park, Malaysia
}

\section{Article Info \\ Article history: \\ Received Sep 28, 2018 \\ Revised Nov 26, 2018 \\ Accepted Dec 10, 2018}

\section{Keywords:}

Active inductor

Analogue pre-distorter

Bluetooth low energy

CMOS

Power amplifier

\begin{abstract}
In this paper, a low power consumption linear power amplifier (PA) for Bluetooth Low Energy (BLE) application is presented. An analogue predistorter (APD) is integrated to the PA. The APD consist of an active inductor, driver amplifier, and a RC phase linearizer. The PA delivers more than $12 \mathrm{~dB}$ power gain from $2.4 \mathrm{GHz}$ to $2.5 \mathrm{GHz}$. At the center frequency of $2.45 \mathrm{GHz}$, the gain of the PA is $13 \mathrm{~dB}$ with $\mathrm{PAE}$ of $26.7 \%$ and maximum output power of $14 \mathrm{dBm}$. The corresponding OIP3 is $27.6 \mathrm{dBm}$. The supply voltage headroom of this PA is $1.8 \mathrm{~V}$. The propose APD serves to be a solution to improve the linearity of the PA with minimum trade-off to the power consumption.
\end{abstract}

Copyright () 2019 Institute of Advanced Engineering and Science. All rights reserved.

\section{Corresponding Author:}

Jagadheswaran Rajendran,

Collaborative Microelectronic Design Excellence Centre (CEDEC),

Universiti Sains Malaysia,

Sains@USM Level 1, Block C No. 10, Lebuh Bukit Jambul, 11900 Bayan Lepas, Pulau Pinang, Malaysia.

Email: jaga.rajendran@usm.my

\section{INTRODUCTION}

In recent years, wireless communication system has evolved rapidly to accomplish higher data rate transmission scheme. Wireless communication is aiding in the development of Internet of Things (IoT) which includes communication devices such as Wi-Fi, Zigbee, and Bluetooth.

Bluetooth devices work in the Industrial, Scientific, and Medical (ISM) band which is located at $2.4-2.483 \mathrm{GHz}$. Bluetooth devices is classified into 3 classes based on their data transmission distance. Higher transmission distance requires higher output power from the transmitter. The classes are Class 1, Class2, and Class 3 with maximum output power of $20 \mathrm{dBm}, 4 \mathrm{dBm}$, and $0 \mathrm{dBm}$ respectively [1]. Bluetooth power amplifier usually works in low power mode, which requires the Class 1 power amplifier to be controlled down to $4 \mathrm{dBm}$ or less in a monotonic sequence in order to save the power [2]. Figure 1 depicts the location of the PA in the block diagram of BLE transmitter.

CMOS power amplifier have been broadly examined to satisfy the demand of low cost and minimal size transceivers. Due to the high tradeoff between linearity and efficiency in CMOS PAs as compared to GaAs PAs, arduous challenges have been faced in order to achieve stringent linearity requirements for modern wireless communication system [3-6]. Various intrinsic drawbacks in CMOS PA such as low quality factor, lossy substrate of passive structures, low breakdown voltage, and low trans-conductance of active devices contributes to the difficulty of CMOS PA commercialization. Therefore, numerous exertions 
in terms of linearity enhancement techniques and efficiency enhancement techniques have been implemented on overcoming the drawbacks of CMOS technology for PA designs [7-9].

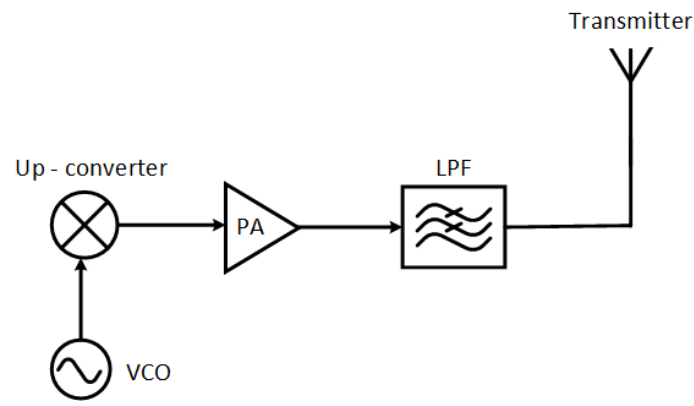

Figure 1. The block diagram of BLE transmitter

A simple linearization technique using passive components have been proposed by P. Gunasegaran et al (2017) for BLE application [10]. A simple RC network is connected at the gate of the transistors which reduces $\mathrm{Cgs}$ effect and thus improves linearity. Moreover, linearization using a simple body network have been proposed by G. Jeong et al (2016) for WLAN application [11]. A linearizing body network is implemented by utilizing a resistor that connect the body and drain node of a power transistor. Also, a common-gate combining PA with load impedance adaptor have been proposed by Y. Jin et al (2017) [12]. The PA is utilized for WLAN application in which the main amplifiers are biased differently to apply the adaptive power cell technique which enhances linearity.

The purpose of this work is to design a linear low power CMOS PA for BLE application. High linearity is targeted to enhance the communication distance while preserving the quality of the data transmitted. An analogue pre-distorter is implemented in the CMOS PA to achieve this target. The outline of this work is arranged as follows. In Section 2, the design methodology of the CMOS PA is described. Section 3 represents the post layout results obtained for the designed CMOS PA. Finally, the conclusion is presented in Section 4.

\section{DESIGN METHODOLOGY}

The schematic diagram of the proposed CMOS power amplifier (PA) with APD is illustrated in Figure 2. Zout APD denotes the output impedance of the APD while Zout Main denotes the output impedance of the main amplifier. The main amplifier is biased at Class AB with quiescent current of $17 \mathrm{~mA}$. The input matching network is represented by $\mathrm{C} 1, \mathrm{C} 2, \mathrm{C} 3$, and $\mathrm{L} 1$. On the other hand, the output matching network is represented by $\mathrm{C} 11, \mathrm{C} 12, \mathrm{C} 13$, and L3. Capacitor C10 functions as a decoupling capacitor to shunt the third order non-linear component produced from the drain supply to ground. Inductor L2 and capacitor C9 nullifies the effect of parasitic drain-source capacitance, Cds, thus improving the PAE of the PA.

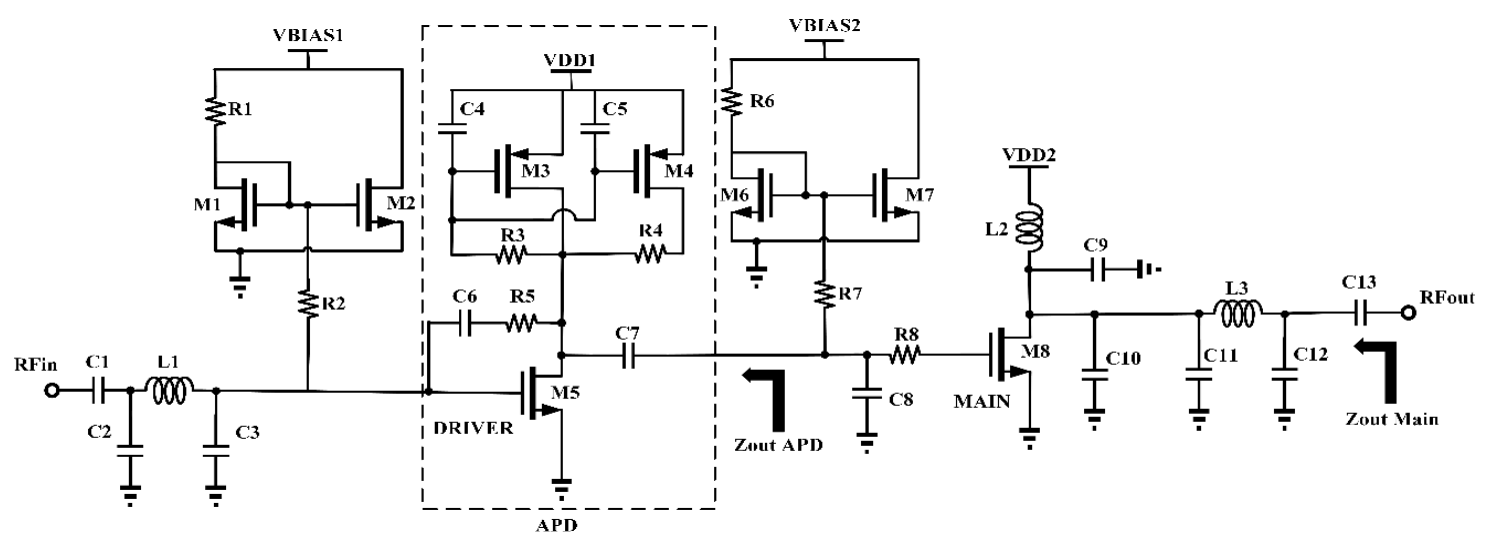

Figure 2. The schematic of the PA with APD 
Figure 3 depicts the AM - PM responses of the APD and main amplifier. The phase response between the APD and main amplifier are opposite to each other and is represented in 1 and 2 respectively.

$$
\begin{aligned}
& {\left[\left(R_{5} R_{3} R_{o 1} R_{o 2} R_{o 3} R_{8}+R_{5} R_{3} R_{4} R_{o 1} R_{o 3} R_{8}\right)-j \omega\left(C_{8} R_{5} R_{3} R_{o 1} R_{o 2} R_{o 3}+C_{8} R_{5} R_{3} R_{4} R_{o 1} R_{o 3}\right.\right.} \\
& +C_{8} R_{3} R_{8} R_{o 1} R_{o 2}+C_{7} R_{3} R_{8} R_{o 1} R_{o 2}+C_{7} R_{3} R_{4} R_{8} R_{o 1}+C_{7} R_{5} R_{8} R_{o 1} R_{o 2}+C_{7} R_{5} R_{8} R_{4} R_{o 1} \\
& +C_{7} R_{3} R_{5} R_{8} R_{o 2}+C_{7} R_{3} R_{4} R_{5} R_{8}+C_{7} R_{3} R_{5} R_{8} R_{o 1}+C_{7} R_{8} R_{o 3}+C_{6} R_{3} R_{8} R_{o 1} R_{o 2} R_{o 3} \\
& \left.\left.+C_{6} R_{3} R_{4} R_{8} R_{o 1} R_{o 3}\right)\right]
\end{aligned}
$$

$$
\begin{aligned}
& Z_{\text {out }} A P D=\frac{}{\left[\left(R_{5} R_{3} R_{o 1} R_{o 2} R_{o 3}+R_{5} R_{3} R_{4} R_{o 1} R_{o 3}\right)-j \omega\left(C_{6} R_{o 1} R_{o 2} R_{o 3} R_{3}+C_{6} R_{3} R_{4} R_{o 1} R_{o 3}+C_{7} R_{o 1} R_{o 2} R_{3}\right.\right.} \\
& +C_{7} R_{o 1} R_{4} R_{3}+C_{7} C_{3} R_{5} R_{o 1} R_{o 2}+C_{7} C_{3} R_{o 3} R_{4}+C_{7} R_{5} R_{3} R_{o 2}+C_{7} R_{3} R_{4} R_{5}+C_{7} R_{3} R_{5} R_{o 1} \\
& +C_{7} R_{o 3}+C_{8} R_{o 1} R_{o 2} R_{3}+C_{8} R_{o 1} R_{4} R_{3}+C_{8} R_{o 1} R_{o 2} R_{5}+C_{8} R_{o 1} R_{4} R_{5}+C_{8} R_{o 2} R_{3} R_{5} \\
& \left.\left.+C_{8} R_{3} R_{4} R_{5}+C_{8} R_{3} R_{5} R_{o 1}+C_{8} R_{o 3}\right)\right]
\end{aligned}
$$

where Ro1, Ro2, and Ro3 are the resistor representation of the channel length modulation of transistors M3, M4, and M5 respectively.

$$
\begin{aligned}
& j \omega\left(C_{10} C_{11} C_{12} R_{o 4}+C_{10} C_{11} C_{13} R_{o 4}+C_{10} C_{12} C_{13} R_{o 4}-C_{10} C_{12} L_{3} R_{o 4}\right. \\
& \left.-C_{10} C_{13} L_{3} R_{o 4}+C_{11} C_{12} C_{13} R_{o 4}-C_{11} C_{12} L_{3} R_{o 4}-C_{11} C_{13} L_{3} R_{o 4}\right) \\
& Z_{\text {out }} \text { MAIN }=\frac{\left[\left(C_{11} L_{3} R_{o 4}-C_{11} C_{12} R_{o 4}+C_{10} L_{3} R_{o 4}-C_{10} C_{12} R_{o 4}\right.\right.}{} \\
& \left.\left.-C_{11} C_{1} R_{o 4}\right)+j \omega\left(C_{10} C_{11} C_{12}-C_{10} C_{11} L_{3}\right)\right]
\end{aligned}
$$

where Ro4 is the resistor representation of channel length modulation of transistor M8.

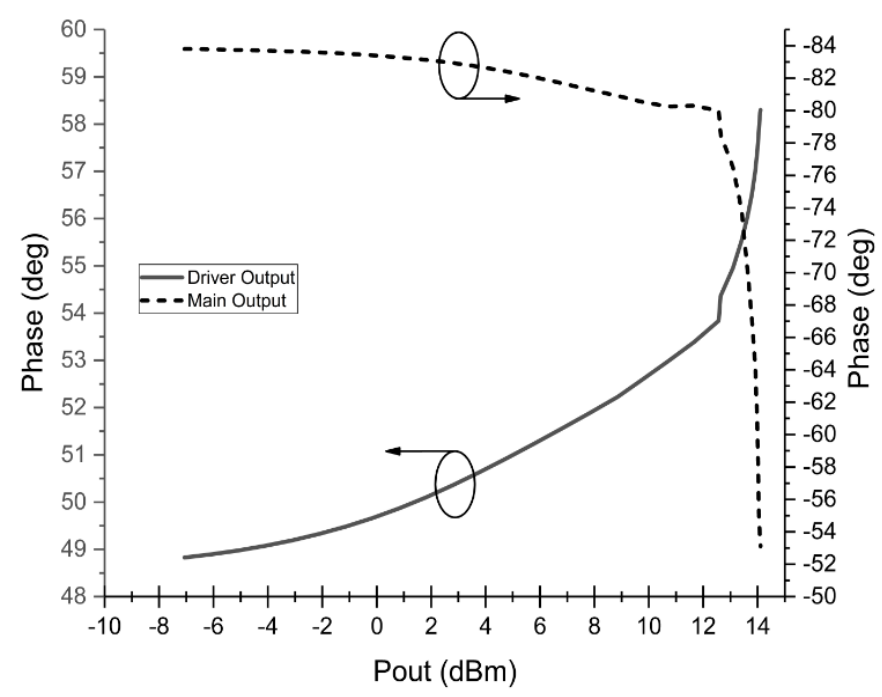

Figure 3. The AM-PM responses of the APD and main amplifier

\section{VALIDATION RESULTS}

The small signal parameters of the PA is as shown in Figure 4. At the center frequency of $2.45 \mathrm{GHz}$, the PA produces a gain of $13 \mathrm{~dB}$. The $\mathrm{S} 11$ and $\mathrm{S} 22$ value of the PA are $-19.5 \mathrm{~dB}$ and $-19.7 \mathrm{~dB}$ respectively which provides a good reverse isolation of both input and output. 


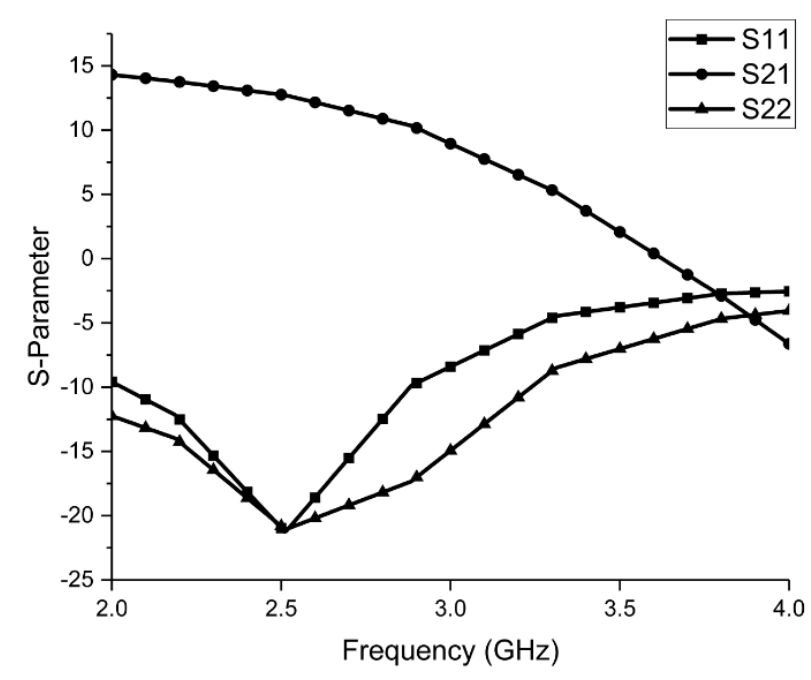

Figure 4. Small signal parameters of the designed PA

The stability factor of the PA is depicted in Figure 5. It can be observed from the figure that the PA is unconditionally stable across the frequency of $1 \mathrm{GHz}$ to $5 \mathrm{GHz}$.

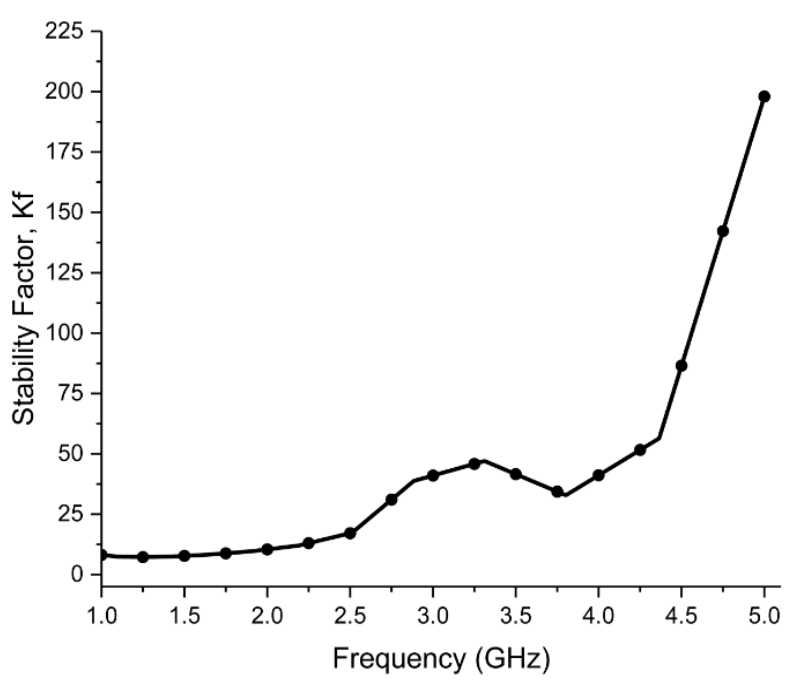

Figure 5. The stability factor of the PA is unconditionally stable

Figure 6 shows power gain, PAE, and OIP3 of the PA. The power gain of the PA across output power shows a flat gain is achieved up to $1 \mathrm{~dB}$ compression point. The maximum delivered output power is $14.1 \mathrm{dBm}$ while the $1 \mathrm{~dB}$ compressed output power $\left(\mathrm{P}_{1 \mathrm{~dB}}\right)$ is $12.6 \mathrm{dBm}$. The PA achieves a peak power added efficiency (PAE) of $26.7 \%$ at the center frequency of $2.45 \mathrm{GHz}$. In addition, the linearity of the PA is presented in terms of output third order intermodulation product (OIP3). The PA produces maximum OIP3 of $27.6 \mathrm{dBm}$ when a dual tone signal with $1 \mathrm{MHz}$ spacing is injected to the input of the PA. At this point, the phase cancellation is maximum. 


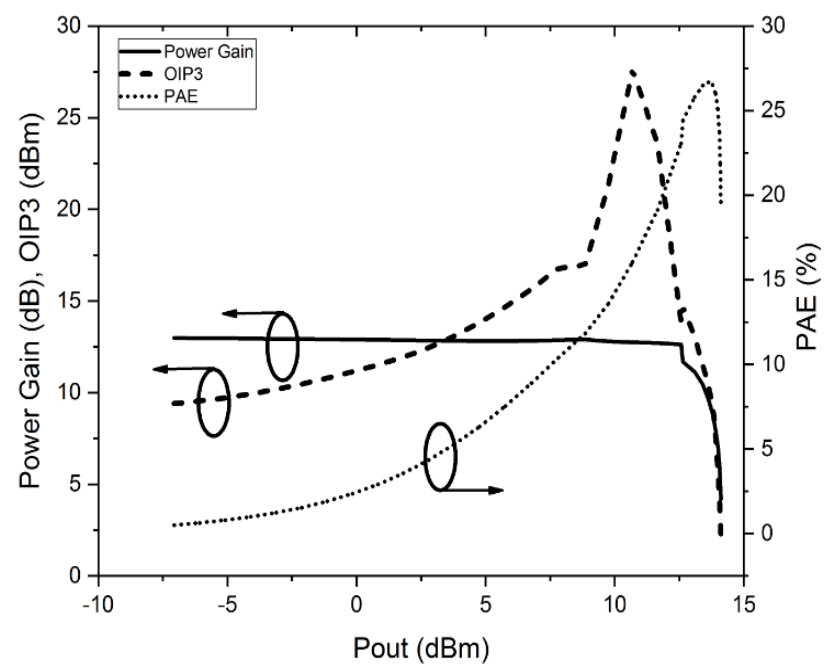

Figure 6. The power gain, PAE, and OIP3 achieved by the PA

The layout of the designed PA is depicted in Figure 7. The chip size of the PA is 1678um x 1748um including the pads for measurement. The post layout simulation performance of the PA is summarized in Table 1. On the other hand, the recent works on low power CMOS PA is summarized and compared in Table 2.

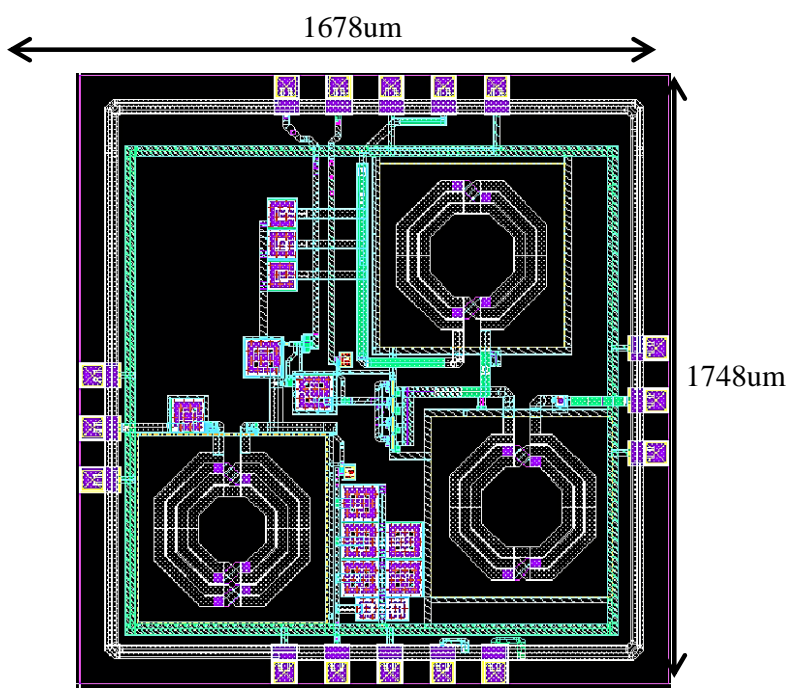

Table 1. Post Layout Simulation Performance of

\begin{tabular}{lc}
\multicolumn{2}{c}{ the PA } \\
\hline Operating Frequency & $2.45 \mathrm{GHz}$ \\
Bandwidth & $100 \mathrm{MHz}$ \\
Power Gain, S21 & $12.9 \mathrm{~dB}$ \\
Input Return Loss, S11 & $-19.5 \mathrm{~dB}$ \\
Output Return Loss, S22 & $-19.7 \mathrm{~dB}$ \\
Peak PAE & $26.7 \%$ \\
Max. Output Power & $14.1 \mathrm{dBm}$ \\
OIP3 & $27.6 \mathrm{dBm}$ \\
Power Supply Voltage & $1.8 \mathrm{~V}$ \\
Technology & $180 \mathrm{~nm}$ \\
& CMOS \\
\hline
\end{tabular}

Figure 7. The layout of the designed PA

Table 2. Work Comparison with Published Power Amplifiers

\begin{tabular}{|c|c|c|c|c|c|c|c|c|}
\hline Ref & PA Tech. & $\begin{array}{l}\text { Supply } \\
\text { (V) }\end{array}$ & $\begin{array}{c}\text { Max Linear Pout } \\
(\mathrm{dBm})\end{array}$ & $\begin{array}{c}\text { Peak } \\
\text { PAE }(\%)\end{array}$ & $\begin{array}{l}\text { Gain } \\
(\mathrm{dB})\end{array}$ & $\begin{array}{l}\text { Freq. } \\
(\mathrm{GHz})\end{array}$ & Linearity & Application \\
\hline$[10]$ & $180 \mathrm{~nm}$ & 1.8 & 13 & 38.4 & 10 & 2.45 & 20.6dBm (OIP3) & BLE \\
\hline [11] & $55 \mathrm{~nm}$ & 3.3 & 16 & 16 & 30 & 2.45 & $-34 \mathrm{dBc}(\mathrm{IMD} 3)$ & WLAN \\
\hline$[12]$ & $180 \mathrm{~nm}$ & 3.3 & 22.08 & 31.97 & 30.7 & 2.4 & - & WLAN \\
\hline [13] & $130 \mathrm{~nm}$ & 2.0 & 19 & 32 & 31 & 2.5 & - & - \\
\hline$[14]$ & $180 \mathrm{~nm}$ & 3.3 & 16.5 & 36.6 & 22 & 0.6 & - & IoT \\
\hline $\begin{array}{l}\text { This } \\
\text { work }\end{array}$ & $180 \mathrm{~nm}$ & 1.8 & 12.6 & 27.6 & 13 & 2.45 & $27.6 \mathrm{dBm}$ & BLE \\
\hline
\end{tabular}

Low voltage CMOS power amplifier with integrated analog Pre-Distorter for... (Selvakumar Mariappan) 


\section{CONCLUSION}

In this paper, an 180nm CMOS PA was designed with an integrated analogue pre-distorter (APD) in which an active inductor is a part of it. The APD improves the linear output power of the PA for low power BLE power amplifier. The PA achieved an OIP3 of $27.6 \mathrm{dBm}$ with maximum PAE of $26.7 \%$, as well as maximum output power of $14.1 \mathrm{dBm}$. Hence, the proposed PA design serves as a good solution to be integrated with a low power BLE transceiver.

\section{ACKNOWLEDGEMENTS}

This research work is funded by Collaborative Research in Engineering, Science and Technology (CREST) [304/PELECT/6050378/C121] and Universiti Sains Malaysia [304/PCEDEC/6315056].

\section{REFERENCES}

[1] Specification of the Bluetooth System, "BLUETOOTH SPECIFICATION Version $2.0+$ EDR", vol 3, pp. 31, Nov. 2004.

[2] V. Vathulya, T. Sowlati, and D. M. W. Leenaerts, Class-1 Bluetooth power amplifier with 24-dBm output power and $48 \%$ PAE at $2.4 \mathrm{GHz}$ in $0.25 \square \mathrm{m} \mathrm{CMOS,"} \mathrm{Proc.} \mathrm{of} \mathrm{27th} \mathrm{European} \mathrm{Solid-State} \mathrm{CircuitsConf.} \mathrm{ESSCIRC,} \mathrm{2001,}$ pp. 84-87.

[3] B. Koo, Y. Na, and S. Hong, "Integrated bias circuits of RF CMOS cascode power amplifier for linearity enhancement," IEEE Trans. Microw. Theory Techn., vol. 60, no. 2, pp. 340-351, Feb 2012.

[4] S. Jin, B. Park, K. Moon, M. Kwon, and B. Kim, "Linearization of CMOS cascode power amplifiers through adaptive bias control," IEEE Trans. Microw. Theory Techn., vol. 61, no. 12, pp. 4534-4543, Dec 2013.

[5] E. Kaymaksut and P. Reynaert, "Dual-mode CMOS Doherty LTE power amplifier with symmetric hybrid transformer,” IEEE J. Solid-State Circuits, vol. 50, no. 9, pp. 1974-1987, Sep 2015.

[6] K. Oishi et al., "A $1.95 \mathrm{GHz}$ fully integrated envelope elimination and restoration CMOS power amplifier using timing alignment technique for WCDMA and LTE," IEEE J. Solid State Circuits, vol. 49, no. 12, pp. 2915-2924, Dec 2014.

[7] Gwanghyeon Jeong, Bonhoon Koo, Taehwan Joo, and Songcheol Hong, "Linearization of RF CMOS Power Amplifier," IEEE Inter. Symposium on Radio Frequency Integration Technology, 2015, Korea, pp 154-156.

[8] P. Asbeck and C. Fallesen, "A $29 \mathrm{dBm} 1.9 \mathrm{GHz}$ class B power amplifier in a digital CMOS process," Proc. ICECS, 2000, vol. 1, pp. 17-20.

[9] T. C. Kuo and B. Lusignan, “A 1.5 W class-F RF power amplifier in $0.2 \mathrm{~m}$ CMOS technology,” ISSCC Dig. Tech. Papers, 2001, pp. 154-155.

[10] P. Gunasegaran, J. Rajendran and H. Ramiah, "A CMOS 180nm class-AB power amplifier with intergrated phase linearizer for BLE 4.0 achieving 11.5dB gain, 38.4\% PAE and 20dBm OIP3," 2017 IEEE Asia Pacific Conference on Postgraduate Research in Microelectronics and Electronics (PrimeAsia), Kuala Lumpur, Malaysia, 2017, pp. 61-64.

[11] G. Jeong, S. Kang, T. Joo and S. Hong, "An Integrated Dual-Mode CMOS Power Amplifier With Linearizing Body Network," IEEE Transactions on Circuits and Systems II: Express Briefs, vol. 64, no. 9, pp. 1037-1041, Sept 2017.

[12] Y. Jin and S. Hong, "A 2.4-GHz CMOS Common-Gate Combining Power Amplifier With Load Impedance Adaptor," IEEE Microwave and Wireless Components Letters, vol. 27, no. 9, pp. 836-838, Sept 2017.

[13] H. Madureira, A. Gros, N. Deltimple, M. Dematos, S. Haddad, D. Belot and E. Kerherve, "Design and measurement of a $2.5 \mathrm{GHz}$ switched-mode CMOS power amplifier with reliability enhancement," 2016 IEEE MTT-S International Wireless Symposium (IWS), Shanghai, 2016, pp. 1-4.

[14] J. Cui, K. Zhang and T. Tian, "A dual-level and dual-band class-D CMOS power amplifier for iot applications," 2013 IEEE 11th International New Circuits and Systems Conference (NEWCAS), Paris, 2013, pp. 1-4.

\section{BIOGRAPHIES OF AUTHORS}

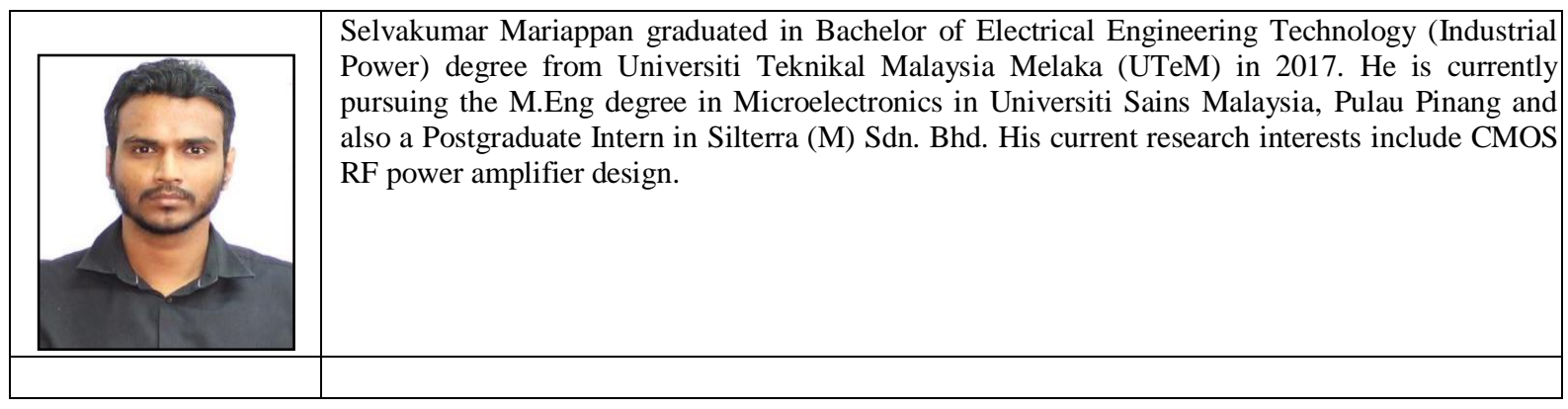

Indonesian J Elec Eng \& Comp Sci, Vol. 14, No. 2, May 2019 : 895 - 902 







\begin{tabular}{|l|l|}
\hline & $\begin{array}{l}\text { Shukri Korakkottil Kunhi Mohd graduated BEng (mechatronic) and MSc (electronic) degrees } \\
\text { from Universiti Sains Malaysia (USM) in } 2006 \text { and 2011, respectively. Currently, he is pursuing } \\
\text { doctoral postgraduate study as part time student in device modeling and characterization at } \\
\text { USM. Besides that, he is working as a research officer at Collaborative Micro-Electronic Design } \\
\text { Excellence Center (CEDEC), USM. }\end{array}$ \\
\hline & $\begin{array}{l}\text { Yusman Mohd. Yusof received his BEng degree in electronic and computer engineering from } \\
\text { Universiti Putra Malaysia (UPM) in 1999. He is currently working at Silterra (M) Sdn. Bhd. } \\
\text { focusing on devices characterization and models development including the radio frequency } \\
\text { (RF) and electrostatic discharge (ESD). }\end{array}$ \\
\hline
\end{tabular}

